\title{
The Extension of the GVW Algorithm to Valuation Domains
}

\author{
Dongmei Li $(\mathbb{D})$ and Licui Zheng $(\mathbb{D}$ \\ School of Mathematics and Computations, Hunan University of Science and Technology, Xiangtan 411201, Hunan, China
}

Correspondence should be addressed to Licui Zheng; zhenglicui@126.com

Received 6 April 2021; Accepted 24 May 2021; Published 7 June 2021

Academic Editor: Hou-Sheng Su

Copyright (c) 2021 Dongmei Li and Licui Zheng. This is an open access article distributed under the Creative Commons Attribution License, which permits unrestricted use, distribution, and reproduction in any medium, provided the original work is properly cited.

The GVW algorithm is an effective algorithm to compute Gröbner bases for polynomial ideals over a field. Combined with properties of valuation domains and the idea of the GVW algorithm, we propose a new algorithm to compute Gröbner bases for polynomial ideals over valuation domains in this study. Furthermore, we use an example to demonstrate the improvement of our algorithm.

\section{Introduction}

The notion of Gröbner basis was first put forward by Buchberger [1]. The theory of Gröbner has been widely applied in numerous fields such as engineering, signal processing, neuroscience, coding theory, complexity, and control of networked dynamical systems and so on. For example, in the theory of symbolic dynamic systems, the problems of determining whether there is a shift equivalence of lag from one nonnegative matrix to another can be transferred into solving large-scale equations, while the latter can be solved by the Gröbner basis theory [2-13].

Seeking more efficient algorithms for the computation of Gröbner bases is a problem in which many researchers cared about extremely [14-19]. Faugère [19] proposed a fast algorithm called F5 for computing Gröbner bases. In this algorithm, he introduced two notions of rewriting and signatures, which allow them to filter the useless S-polynomials in a rather convenient way. A new algorithm named G2V [20] for computing Gröbner bases is presented by Gao et al., which is an algorithm of incremental signature and based on a simple theory. A few months later, they gave an extend version named the GVW algorithm [21]. We are particularly interested in the GVW algorithm which not only matches the original algorithm given by Buchberger in simplicity but also more effective than F5 under some term orders. The algorithms mentioned above are applied to polynomial ideals over fields.

Several algorithms have been widely investigated for Gröbner bases to rings, such as Euclidean domain, principle ideal domain, and valuation rings that may contain zero divisors [22-24].

In this study, we aim to extend the GVW algorithm to valuation domains and present a signature-based algorithm to compute Gröbner bases for ideals in $R=V\left[x_{1}, \ldots, x_{n}\right]$, where $V$ is a valuation domain. In this algorithm, we study relations between J pairs and propose a new concept named factor, which allows us to filter the useless J pairs in a rather convenient way.

The structure of the study is arranged as follows: some basic concepts of the Gröbner basis theory is given in Section 2. In Section 3, we propose theory for the GVW algorithm over valuation domains and obtain main results of this study. Then, we present the new algorithm and demonstrate the improvement clearly by an example in Section 4 .

\section{Preliminaries}

Let $V$ be a valuation ring. For any two nonzero elements $a, b \in V$, there always exists $a \mid b$ or $b \mid a$. The term order for monomials in $R=V\left[x_{1}, \ldots, x_{n}\right]$ is arbitrary throughout this section. The form of the monomial in $R$ is 


$$
x^{\alpha}=x_{1}^{a_{1}}, x_{2}^{a_{2}}, \ldots, x_{n}^{a_{n}}
$$

where $\alpha=\left(a_{1}, a_{2}, \ldots, a_{n}\right) \in \mathbb{N}^{n}$. The definition of the leading monomial (abbreviated as $\mathrm{lm}$ ), the leading term (abbreviated as lt), and the leading coefficient (abbreviated as lc) of a given polynomial is as usual.

A nonzero polynomial set $G_{w}$ in an ideal $I$ is named as (weak) Gröbner basis for $I$ if

$$
\left\langle\operatorname{lt}\left(G_{w}\right)\right\rangle=\operatorname{lt}(I) .
$$

This does not imply that, for each $f \in I$, there exists some polynomial $g \in G_{w}$, so that $\operatorname{lt}(g) \mid \operatorname{lt}(f)$. For example, $I=\langle 2 x, 3 y\rangle \subset \mathbb{Z}[x, y]$ has a Gröbner basis $G=\{2 x, 3 y\}$, and $x y=-y(2 x)+x(3 y) \in I$, but $x y$ is not divisible by $2 x$ nor $3 y$ in $\mathbb{Z}[x, y]$.

Definition 1. A set $G_{s}$ is called a strong Gröbner basis for $I$ if $\forall f \in I$, and there is a polynomial $g \in G_{s}$, so that $\operatorname{lt}(g) \mid \operatorname{lt}(f)$, where $G_{s}$ is formed by the nonzero polynomials from $I$.

For the above example, $\{2 x, 3 y, x y\}$ is a strong Gröbner basis of the ideal $I$, but the set $\{2 x, 3 y\}$ is not. This shows already some difference when dealing with polynomials over rings from those over fields.

Proposition 1. Suppose $V$ is a valuation domain. Then, every ideal in $V\left[x_{1}, \ldots, x_{n}\right]$ has a strong Gröbner basis.

Proof. It can be easily obtained by properties of valuation ring.

We now follow the notations in [21]. Let $R=V\left[x_{1}, \ldots, x_{n}\right]$, where $V$ denotes a valuation domain, and $h_{1}, \ldots, h_{m} \in R$ are the polynomials. Let

$$
\begin{aligned}
I & =\left\langle h_{1}, \ldots, h_{m}\right\rangle \\
& =\left\{p_{1} h_{1}+\cdots+p_{m} h_{m}:\left(p_{1}, \ldots, p_{m}\right) \in R^{m}\right\} \subseteq R
\end{aligned}
$$

be an ideal, and its Gröbner basis is what we want to obtain. Vectors in $R^{m}$ are denoted by bold letters, for example, $\mathbf{p}=\left(p_{1}, \ldots, p_{m}\right)$. Let $\mathbf{e}_{j}$ be the $j^{\text {th }}$ unit vector in $R^{m}$ for $1 \leq j \leq m$. Define an $R$ submodule of $R^{m} \times R$ :

$M=\left\{(\mathbf{p}, f) \in R^{m} \times R: \mathbf{p h}^{t}=f\right.$, that is, $\left.p_{1} h_{1}+\cdots+p_{m} h_{m}=v\right\}$.

Note that, as an $R$ module, $M$ is generated by

$$
\left(\mathbf{e}_{1}, h_{1}\right),\left(\mathbf{e}_{2}, h_{2}\right), \ldots,\left(\mathbf{e}_{m}, h_{m}\right) .
$$

$\mathbf{H}=\left\{\left(p_{1}, \ldots, p_{m}\right) \in R^{m}: p_{1} h_{1}+\cdots+p_{m} h_{m}=0\right\}$ is defined to be the syzygy module of $\mathbf{h}=\left(h_{1}, \ldots, h_{m}\right)$. We shall see that the big module $M$ allows us to get the Gröbner bases for $I$ and $\mathbf{H}$ in the same time and allows us to develop a criterion to detect useless $S$ polynomials.

We define quasiordering in $V$ : for arbitrary $a, b \in V$, we say $a \prec b$ if $a \mid b$. Following this definition, then a term order (throughout this study, by a monomial order, we mean a global ordering [21]) $\leq$ on $R$ is defined by $a_{1} t_{1} \leq a_{2} t_{2}$ iff

$$
\begin{array}{r}
t_{1} \leq t_{2} \\
\text { or } t_{1}=t_{2}, \\
a_{1} \mid a_{2} .
\end{array}
$$

We assume $R^{m}$ has a term order that is compatible with that of $R$. We refer the readers to [21] for several examples on how term order of $R$ can be extended to $R^{m}$. Note that a term in $R^{m}$ is the form as

$$
x^{\alpha} e_{i}
$$

for some $\alpha \in \mathbb{N}^{m}$ and $1 \leq i \leq m$. For any nonzero $\mathbf{p} \in R^{m}$,

$$
\operatorname{lt}(\mathbf{p})=\operatorname{lc}(\mathbf{p}) \cdot \operatorname{lm}(\mathbf{p})
$$

where $\operatorname{lm}(\mathbf{p})$ is the leading monomial of $\mathbf{p}$, and $\operatorname{lc}(\mathbf{p}) \in V$ is the leading coefficient of $\mathbf{p}$.

\section{Theory of the Algorithm}

In this section, we present the theory of our algorithm. First, some basic definitions are needed.

Definition 2. $\operatorname{lt}(\mathbf{p})$ is said to be the signature of $(\mathbf{p}, f)$, where $(\mathbf{p}, f) \in R^{m} \times R$.

Definition 3. We say $\left(\mathbf{p}_{1}, f_{1}\right) \in R^{m} \times R$ can be top-reduced by $\left(\mathbf{p}_{2}, f_{2}\right) \in R^{m} \times R\left(\operatorname{lt}\left(f_{2}\right) \neq 0\right)$ when they meet the following two conditions:

(i) $\operatorname{lt}\left(f_{2}\right)$ divides $\operatorname{lt}\left(f_{1}\right)$ (i.e., $f_{2}$ is top-divisible by $\left(f_{1}\right)$ ) and

(ii) $\operatorname{lt}\left(t \cdot \mathbf{p}_{2}\right) \prec \operatorname{lt}\left(\mathbf{p}_{1}\right)$, where $t=\operatorname{lt}\left(f_{1}\right) / \operatorname{lt}\left(f_{2}\right)$

Then, the relevant top-reduction is

$$
\left(\mathbf{p}_{1}, f_{1}\right)-t\left(\mathbf{p}_{2}, f_{2}\right)=\left(\mathbf{p}_{1}-t \mathbf{p}_{2}, f_{1}-t f_{2}\right) \text {. }
$$

Hence, we can divide this reduction into two types; one is called regular when

$$
\operatorname{lm}\left(t \mathbf{p}_{2}\right)<\operatorname{lm}\left(\mathbf{p}_{1}\right)
$$

and the other is called super if

$$
\frac{\operatorname{lt}\left(\mathbf{p}_{1}\right)}{\operatorname{lt}\left(\mathbf{p}_{2}\right)}=\frac{\operatorname{lt}\left(f_{1}\right)}{\operatorname{lt}\left(f_{2}\right)} \text {. }
$$

Besides, there is another super top-reduction, that is, when $f_{2}=0$, we say that $\left(\mathbf{p}_{1}, f_{1}\right)$ is super top-reduced by $\left(\mathbf{p}_{2}, 0\right)$ if $\mathbf{p}_{1}$ and $\mathbf{p}_{2}$ are both nonzero and $\operatorname{lt}\left(\mathbf{p}_{2}\right)$ divides $\operatorname{lt}\left(\mathbf{p}_{1}\right)$. So when a pair $\left(\mathbf{p}_{1}, f_{1}\right)$ can be reduced by $\left(\mathbf{p}_{2}, 0\right)$, we just reduce the signature of $\left(\mathbf{p}_{1}, f_{1}\right)$ but without increasing $\operatorname{lt}\left(f_{1}\right)$ (even if $\left.f_{1}=0\right)$. What attracts more of our attention is that $\left(\mathbf{p}_{1}, 0\right)$ is never top-reduced by $\left(\mathbf{p}_{2}, f_{2}\right)$ when $f_{2} \neq 0$.

Similar to Definition 1, we give the definition of strong Gröbner basis for $M$ in the following.

Definition 4. Suppose $G_{s}$ is a subset of $M, G_{s}$ is said to be a strong Gröbner basis of $M$, if every pair $(\mathbf{p}, f) \in M$ can be top-reduced by at least one pair in $G_{s}$. 
It is easy to draw a conclusion from this definition, that is, every pair in $M$ can be top-reduced to 0 by its strong Gröbner basis.

Lemma 1. If $G_{s}$ is a strong Gröbner basis of $M$, where $G_{s}=\left\{\left(\mathbf{p}_{1}, f_{1}\right), \ldots,\left(\mathbf{p}_{k}, f_{k}\right)\right\}$, then

(1) A strong Gröbner basis for the syzygy module of $\mathbf{h}=$ $\left(h_{1}, \ldots, h_{m}\right)$ exists, which is $G_{0}=\left\{\mathbf{p}_{i}: f_{i}=\right.$ $0,1 \leq i \leq k\}$

(2) The strong Gröbner basis for $I=\left\langle h_{1}, \ldots, h_{m}\right\rangle$ also exists, which is $G_{1}=\left\{f_{i}: 1 \leq i \leq k\right\}$

Proof. Assume $\mathbf{p}=\left(p_{1}, \ldots, p_{m}\right)$ is an element from the syzygy module of $\mathbf{h}$, then $(\mathbf{p}, 0) \in M$, and there must exist some pair $\left(\mathbf{p}_{i}, f_{i}\right)$ in $G_{s}$ that can top-reduce $(\mathbf{p}, 0)$ with $f_{i}=0$. Thus, $\mathbf{p}_{i} \in G_{0}$ and $\operatorname{lt}(\mathbf{p})$ can be reduced by $\operatorname{lt}\left(\mathbf{p}_{i}\right)$. This tell us that $G_{0}$ is the set we need, which is a Gröbner basis for the syzygy module of $\mathbf{h}$.

For an arbitrary nonzero polynomial $v \in I$, there is $\mathbf{p}=\left(p_{1}, \ldots, p_{m}\right) \in R^{m}$, such that $\mathbf{p h}^{t}=f$ according to the definition of $R^{m}$ and then (p, $f$ ) $\in M$. Among all such $\mathbf{p}$, we choose the minimum lt $(\mathbf{p})$. By our assumption, there exists at least one pair in $G$ which can top-reduce $(\mathbf{p}, f)$.

If $f=0$, then $(\mathbf{p}, f)$ can be reduced by $\left(\mathbf{p}_{i}, 0\right)$ and get $\left(p^{\prime}, f\right)$, but $p^{\prime} \mathbf{h}^{t}=f$, which contradicts the minimality of $\operatorname{lt}(\mathbf{p})$ as $\operatorname{lt}\left(p^{\prime}\right)<\operatorname{lt}(\mathbf{p})$. So there exists $\left(\mathbf{p}_{i}, f_{i}\right) \in G_{1}$ with $f_{i} \neq 0$ and $\operatorname{lt}\left(f_{i}\right) \mid \operatorname{lt}(f)$. Hence, $G_{1}$ is a Gröbner basis of $I$.

Definition 5. For any pair, $P_{1}=\left(\mathbf{p}_{1}, f_{1}\right), P_{2}=\left(\mathbf{p}_{2}, f_{2}\right) \in R^{m}$ $\times R$, and $f_{1} \neq 0, f_{2} \neq 0$. Let

$$
\begin{aligned}
t & =\operatorname{lcm}\left(\operatorname{lm}\left(f_{1}\right), \operatorname{lm}\left(f_{2}\right)\right), \\
t_{1} & =\frac{t}{\operatorname{lm}\left(f_{1}\right)}, \\
t_{2} & =\frac{t}{\operatorname{lm}\left(f_{2}\right)} .
\end{aligned}
$$

(i) If $\max \left(\operatorname{lm}\left(t_{1} \mathbf{p}_{1}\right), \operatorname{lm}\left(t_{2} \mathbf{p}_{2}\right)\right)=t_{1} \operatorname{lm}\left(\mathbf{p}_{1}\right)$, define

$$
J\left(P_{1}, P_{2}\right)= \begin{cases}t_{1} P_{1}, & \text { if } \operatorname{lc}\left(f_{2}\right) \mid \operatorname{lc}\left(f_{1}\right), \\ \frac{\operatorname{lc}\left(f_{2}\right)}{\operatorname{lc}\left(f_{1}\right)} t_{1} P_{1}, & \text { if } \operatorname{lc}\left(f_{1}\right) \mid \operatorname{lc}\left(f_{2}\right) .\end{cases}
$$

(ii) If $\max \left(\operatorname{lm}\left(t_{1} \mathbf{p}_{1}\right), \operatorname{lm}\left(t_{2} \mathbf{p}_{2}\right)\right)=t_{2} \operatorname{lm}\left(\mathbf{p}_{2}\right)$, define

$$
J\left(P_{1}, P_{2}\right)= \begin{cases}\frac{\operatorname{lc}\left(f_{1}\right)}{\operatorname{lc}\left(f_{2}\right)} t_{2} P_{2}, & \text { if } \operatorname{lc}\left(f_{2}\right) \mid \operatorname{lc}\left(f_{1}\right), \\ t_{2} P_{2}, & \text { if } \operatorname{lc}\left(f_{1}\right) \mid \operatorname{cc}\left(f_{2}\right) .\end{cases}
$$

Remark 1. With notations as above, we do not define J pair for $P_{1}=\left(\mathbf{p}_{1}, f_{1}\right)$ and $P_{2}=\left(\mathbf{p}_{2}, f_{2}\right)$ when one of $f_{1}$ and $f_{2}$ is zero nor when $\operatorname{lm}\left(t_{1} \mathbf{p}_{1}\right)=\operatorname{lm}\left(t_{2} \mathbf{p}_{2}\right)$.

In order to study the relation between J pairs, we propose the following conception:

Definition 6. Suppose $t_{1}\left(\mathbf{p}_{1}, f_{1}\right), t_{2}\left(\mathbf{p}_{2}, f_{2}\right)$ are the J pairs formed from $G$ which is a (finite) subset of $M$, and $t_{1}\left(\mathbf{p}_{1}, f_{1}\right)$ is called a factor of $t_{2}\left(\mathbf{p}_{2}, f_{2}\right)$ if

$$
\begin{aligned}
& a t_{1} \operatorname{lt}\left(\mathbf{p}_{1}\right) w=t_{2} \operatorname{lt}\left(\mathbf{p}_{2}\right), \\
& a t_{1} \operatorname{lt}\left(f_{1}\right) w \prec t_{2} \operatorname{lt}\left(f_{2}\right),
\end{aligned}
$$

for some monomial $a w, a \in V$.

The next result is very useful for reduction.

Lemma 2. Assume at $\left(\mathbf{p}_{j}, f_{j}\right)$ can be regular top-reduced by $\left(\mathbf{p}_{i}, f_{i}\right)$ with neither of $f_{i}, f_{j}$ is zero, where a is an element from $V$ and $t$ is a monomial from $R$; then, $c_{1} t_{1}\left(\mathbf{p}_{j}, f_{j}\right)$ is the J pair of $\left(\mathbf{p}_{i}, f_{i}\right)$ and $\left(\mathbf{p}_{j}, f_{j}\right)$, where

$$
\begin{aligned}
c_{1} & =\frac{\operatorname{lcm}\left(\operatorname{lc}\left(f_{j}\right), \operatorname{lc}\left(f_{i}\right)\right)}{\operatorname{lc}\left(f_{j}\right)}, \\
t_{1} & =\frac{\operatorname{lcm}\left(\operatorname{lm}\left(f_{j}\right), \operatorname{lm}\left(f_{i}\right)\right)}{\operatorname{lm}\left(f_{j}\right)},
\end{aligned}
$$

where $c_{1}$ is a divisor of $a, t_{1} \mid t$, and $\left(\mathbf{p}_{i}, f_{i}\right)$ can regular topreduce $c_{1} t_{1}\left(\mathbf{p}_{j}, f_{j}\right)$.

Proof. By our assumption, there exist $a_{1} \in V$ and a monomial say $w_{1} \in R$, so that

$$
\begin{array}{r}
\operatorname{atlt}\left(f_{j}\right)=a_{1} w_{1} \operatorname{lt}\left(f_{i}\right), \\
w_{1} \operatorname{lm}\left(\mathbf{p}_{i}\right) \prec t \operatorname{lm}\left(\mathbf{p}_{j}\right) .
\end{array}
$$

Set

$$
\begin{aligned}
& c_{2}=\frac{\operatorname{lcm}\left(\operatorname{lc}\left(f_{j}\right), \operatorname{lc}\left(f_{i}\right)\right)}{\operatorname{lc}\left(f_{i}\right)}, \\
& t_{2}=\frac{\operatorname{lcm}\left(\operatorname{lm}\left(f_{j}\right), \operatorname{lm}\left(f_{i}\right)\right)}{\operatorname{lm}\left(f_{i}\right)},
\end{aligned}
$$

we have that

$$
\begin{aligned}
c_{2} t_{2} & =\frac{\operatorname{lcm}\left(\operatorname{lc}\left(f_{j}\right), \operatorname{lc}\left(f_{i}\right)\right)}{\operatorname{lc}\left(f_{i}\right)} \cdot \frac{\operatorname{lcm}\left(\operatorname{lm}\left(f_{j}\right), \operatorname{lm}\left(f_{i}\right)\right)}{\operatorname{lm}\left(f_{i}\right)} \\
& =\frac{\operatorname{lcm}\left(\operatorname{lt}\left(f_{j}\right), \operatorname{lt}\left(f_{i}\right)\right)}{\operatorname{lt}\left(f_{i}\right)} .
\end{aligned}
$$




$$
\begin{aligned}
& a_{2} w_{2} \operatorname{lcm}\left(\operatorname{lt}\left(f_{j}\right), \operatorname{lt}\left(f_{i}\right)\right)=\operatorname{at} \operatorname{lt}\left(f_{j}\right)=a_{1} w_{1} \operatorname{lt}\left(f_{i}\right) . \\
c_{1} t_{1}= & \frac{\operatorname{lcm}\left(\operatorname{lc}\left(f_{j}\right), \operatorname{lc}\left(f_{i}\right)\right)}{\operatorname{lc}\left(f_{j}\right)} \cdot \frac{\operatorname{lcm}\left(\operatorname{lm}\left(f_{j}\right), \operatorname{lm}\left(f_{i}\right)\right)}{\operatorname{lm}\left(f_{j}\right)} \\
= & \frac{\operatorname{lcm}\left(\operatorname{lt}\left(f_{j}\right), \operatorname{lt}\left(f_{i}\right)\right)}{\operatorname{lt}\left(f_{j}\right)} .
\end{aligned}
$$

Thus,

$$
\begin{aligned}
a_{1} w_{1} \operatorname{lt}\left(f_{i}\right) & =a_{2} w_{2} c_{2} t_{2} \operatorname{lt}\left(f_{i}\right), \\
\operatorname{atlt}\left(f_{j}\right) & =a_{2} w_{2} c_{1} t_{1} \operatorname{lt}\left(f_{j}\right), \\
\operatorname{alc}\left(f_{j}\right) & =a_{2} c_{1} \operatorname{lc}\left(f_{j}\right), \\
a_{1} \operatorname{lc}\left(f_{i}\right) & =a_{2} c_{2} \operatorname{lc}\left(f_{i}\right), \\
t & \operatorname{lm}\left(f_{j}\right)=t_{1} w_{2} \operatorname{lm}\left(f_{j}\right), \\
w_{1} \operatorname{lm}\left(f_{i}\right) & =t_{2} w_{2} \operatorname{lm}\left(f_{i}\right) .
\end{aligned}
$$

Then, we have that

$$
\begin{gathered}
a=a_{2} c_{1}, \\
a_{1}=a_{2} c_{2}, \\
c_{1} \mid a, \\
t=t_{1} w_{2}, \\
w_{1}=t_{2} w_{2} .
\end{gathered}
$$

Hence, $c_{1} t_{2} \operatorname{lt}\left(\mathbf{p}_{i}\right)<c_{2} t_{1} \operatorname{lt}\left(\mathbf{p}_{j}\right)$ as $\operatorname{sim}\left(\mathbf{p}_{i}\right)<t \operatorname{lm}\left(\mathbf{p}_{j}\right)$. Thus, $\max \left(t_{2} \operatorname{lm}\left(\mathbf{p}_{i}\right), t_{1} \operatorname{lm}\left(\mathbf{p}_{j}\right)\right)=t_{1} \operatorname{lm}\left(\mathbf{p}_{i}\right)$. And the $\mathrm{J}$ pair of $\left(\mathbf{p}_{j}, f_{j}\right)$ and $\left(\mathbf{p}_{i}, f_{i}\right)$ is $c_{1} t_{1}\left(\mathbf{p}_{j}, f_{j}\right)$ by Definition 5 . Note that

$$
\operatorname{atlt}\left(f_{1}\right)=a_{1} w_{1} \operatorname{lt}\left(f_{2}\right) \text {, }
$$

and then,

$$
a_{2} c_{1} t_{1} w_{2} \operatorname{lt}\left(f_{j}\right)=a_{2} c_{2} t_{2} w_{2} \operatorname{lt}\left(f_{i}\right) .
$$

Therefore,

$$
\operatorname{lt}\left(f_{i}\right) \mid c_{1} t_{1} \operatorname{lt}\left(f_{j}\right) .
$$

We see that $\left(\mathbf{p}_{i}, f_{i}\right)$ can regular top-reduce $c_{1} t_{1}\left(\mathbf{p}_{j}, f_{j}\right)$.

Suppose $S$ is a set formed by the pairs in $R^{m} \times R$, we say $S$ can regular (super) top-reduce the pair $(\mathbf{p}, f) \in R^{m} \times R$, if there is at least one pair in $S$ which can regular (super) topreduce the pair $(\mathbf{p}, f)$. Furthermore, we implement a series of such reductions to $(\mathbf{p}, f)$ until it cannot be regular topreduced by this set anymore, but $(\mathbf{p}, f)$ can be super topreduced by $S$, and this reduction defined as $(\mathbf{p}, f)$ is eventually super top-reduced by $S$.

Theorem 1. Suppose $T$ is any term in $R^{m}$, and there always exists a pair $\left(\mathbf{p}_{i}, f_{i}\right)$ in $G_{s}$, a monomial $t \in R$ and $a \in V$, such that $T=\operatorname{atlt}\left(\mathbf{p}_{i}\right)$, where $G_{s}$ is a subset of $M$. Then, $G_{s}$ is a strong Gröbner basis for $M$ if and only if, for the J pairs formed from $G_{s}$ such as $(\mathbf{p}, f)$, there always exists a pair $\left(\mathbf{p}_{1}, f_{1}\right) \in G_{s}$, so that $l t\left(\mathbf{p}_{1}\right) \mid l t(\mathbf{p})$ and $\operatorname{tm}\left(f_{1}\right)<\operatorname{lm}(f)$, where $t=\operatorname{lm}(\mathbf{p}) / \operatorname{lm}\left(\mathbf{p}_{1}\right)$.

Proof. Necessity: let $(\mathbf{p}, f)$ be an arbitrary $\mathrm{J}$ pair formed from $G_{s}$; then, $(\mathbf{p}, f)$ is in $M$, and it is top-reduced by $G_{s}$ as the set $G_{s}$ is a strong Gröbner basis for the module $M$. We can do the regular top-reductions to $(\mathbf{p}, f)$ as much as possible until $(\mathbf{p}, f)$ cannot be regular top-reduced any more, say to get $\left(\mathbf{p}_{0}, f_{0}\right)$. And $\left(\mathbf{p}_{0}, f_{0}\right)$ can be top-reduced by $G_{s}$ as it is still in $M$; but now, the reduction can only be super reduction, say $\left(\mathbf{p}_{0}, f_{0}\right)$ can be super reduced by $\left(\mathbf{p}_{1}, f_{1}\right) \in G_{s}$.

(1) If $f_{1}=0$, then $\operatorname{lt}\left(\mathbf{p}_{1}\right) \mid \operatorname{lt}\left(\mathbf{p}_{0}\right)=\operatorname{lt}(\mathbf{p})$, and $t f_{1}=0$ is smaller than $\operatorname{lm}(f)$, and the conclusion is true.

(2) If $f_{1} \neq 0$,

$$
\begin{aligned}
& t=\frac{\operatorname{lm}\left(f_{0}\right)}{\operatorname{lm}\left(f_{1}\right)}=\frac{\operatorname{lm}\left(\mathbf{p}_{0}\right)}{\operatorname{lm}\left(\mathbf{p}_{1}\right)}, \\
& \frac{\operatorname{lc}\left(f_{0}\right)}{\operatorname{lc}\left(f_{1}\right)} \cdot \operatorname{lc}\left(\mathbf{p}_{1}\right) \prec \operatorname{lc}\left(\mathbf{p}_{0}\right) .
\end{aligned}
$$

Combined with the definition of quasiordering given, we have that

$$
\frac{\operatorname{lc}\left(f_{0}\right)}{\operatorname{lc}\left(f_{1}\right)} \cdot \operatorname{lc}\left(\mathbf{p}_{1}\right) \mid \operatorname{lc}\left(\mathbf{p}_{0}\right)
$$

and then, $\operatorname{lc}\left(\mathbf{p}_{1}\right) \mid \operatorname{lc}\left(\mathbf{p}_{0}\right)$.

Since $\left(\mathbf{p}_{0}, f_{0}\right)$ is obtained by performed regular topreduction to $(\mathbf{p}, f)$, then $\operatorname{lm}\left(f_{0}\right)<\operatorname{lm}(f)$ and $\operatorname{lt}\left(\mathbf{p}_{0}\right)=\operatorname{lt}(\mathbf{p})$; the latter shows that

$$
t \operatorname{lm}\left(f_{1}\right)=\operatorname{lm}\left(f_{0}\right)<\operatorname{lm}(f) .
$$

So, $\operatorname{lt}\left(\mathbf{p}_{1}\right) \mid \operatorname{lt}\left(\mathbf{p}_{0}\right)=\operatorname{lt}(\mathbf{p})$ and $t \operatorname{lm}\left(f_{1}\right)<\operatorname{lm}(f)$.

Sufficiency: suppose there are some pairs in $M$ which cannot be top-reduced the set $G_{s}$, say $(\mathbf{p}, f) \in M$ is such a pair. We prove that such a pair does not exist. Select the minimal signature $T=\operatorname{lt}(\mathbf{p})$ from all such pairs with $\operatorname{lt}(\mathbf{p}) \neq \mathbf{0}$, and we choose a pair $\left(\mathbf{p}_{j}, f_{j}\right)$ from $G_{s}$, so that

(i) $T=a t \operatorname{lt}\left(\mathbf{p}_{j}\right)$ with $a \in V$ and $t$ is a monomial in $R$, and

(ii) $t \operatorname{lm}\left(f_{j}\right)$ is the smallest one among all $1 \leq j \leq k$ satisfying (i)

In the following, we prove that at $\left(\mathbf{p}_{j}, f_{j}\right)$ should not be regular top-reduced by $G_{s}$. Suppose that at $\left(\mathbf{p}_{j}, f_{j}\right)$ could be regular top-reduced by a pair $\left(\mathbf{p}_{i}, f_{i}\right), \quad i \neq j$, then $f_{j} \neq 0, f_{i} \neq 0$. What we expect is to get a conclusion that contradicts condition (ii). From Lemma 2, we have that $c_{1} t_{1}\left(\mathbf{p}_{j}, f_{j}\right)$ is the J pair of $\left(\mathbf{p}_{j}, f_{j}\right)$ and $\left(\mathbf{p}_{i}, f_{i}\right)$; moreover, it can still be regular top-reduced by $\left(\mathbf{p}_{i}, f_{i}\right)$, where 


$$
\begin{aligned}
c_{1} & =\frac{\operatorname{lcm}\left(\operatorname{lc}\left(f_{i}\right), \operatorname{lc}\left(f_{j}\right)\right)}{\operatorname{lc}\left(f_{j}\right)}, \\
t_{1} & =\frac{\operatorname{lcm}\left(\operatorname{lm}\left(f_{j}\right), \operatorname{lm}\left(f_{i}\right)\right)}{\operatorname{lm}\left(f_{j}\right)}, \\
t & =t_{1} w, c_{1} \mid a,
\end{aligned}
$$

for some $c_{1} \in V$ and monomial $w \in R$.

Case 1. If $\operatorname{lc}\left(f_{i}\right) \mid \operatorname{lc}\left(f_{j}\right)$, then $c_{1}=1$, and the J pair of $\left(\mathbf{p}_{i}, f_{i}\right)$ and $\left(\mathbf{p}_{j}, f_{j}\right)$ is $t_{1}\left(\mathbf{p}_{j}, f_{j}\right)$. Note that $t_{1}\left(\mathbf{p}_{j}, f_{j}\right)$ is a $J$ pair formed from $G_{s}$, so there must exists a pair $\left(\mathbf{p}_{\ell}, f_{\ell}\right) \in G_{s}$, so that $\operatorname{lt}\left(\mathbf{p}_{\ell}\right) \mid t_{1} \operatorname{lt}\left(\mathbf{p}_{j}\right) \quad$ and $\quad t_{3} \operatorname{lm}\left(f_{\ell}\right)<t_{1} \operatorname{lm}\left(f_{j}\right) \quad$ with $t_{3}=t_{1} \operatorname{lm}\left(\mathbf{p}_{j}\right) / \operatorname{lm}\left(\mathbf{p}_{\ell}\right)$. Since $\operatorname{lc}\left(\mathbf{p}_{\ell}\right) \mid \operatorname{lc}\left(\mathbf{p}_{j}\right)$, we set $a_{3}=\left(\operatorname{lc}\left(\mathbf{p}_{j}\right) / \operatorname{lc}\left(\mathbf{p}_{\ell}\right)\right)$, and then,

$$
\begin{gathered}
a \cdot a_{3} t_{3} w \operatorname{lt}\left(\mathbf{p}_{\ell}\right)=a \cdot t_{1} w \operatorname{lc}\left(\mathbf{p}_{j}\right) \cdot \operatorname{lm}\left(\mathbf{p}_{j}\right)=a t_{1} w \operatorname{lt}\left(\mathbf{p}_{j}\right)=a \operatorname{lt}\left(\mathbf{p}_{j}\right)=T, \\
t_{3} w \operatorname{lm}\left(f_{\ell}\right)<w t_{1} \operatorname{lm}\left(f_{j}\right)=t \operatorname{lm}\left(f_{j}\right) .
\end{gathered}
$$

This contradicts the condition (ii) for the selection of $\left(\mathbf{p}_{j}, f_{j}\right)$ in $G_{s}$.

Case 2. If $\operatorname{lc}\left(f_{j}\right) \mid \operatorname{lc}\left(f_{i}\right)$, then $c_{1}=\left(\operatorname{lc}\left(f_{i}\right) / \operatorname{lc}\left(f_{j}\right)\right)$, and the $\mathrm{J}$ pair of $\left(\mathbf{p}_{i}, f_{i}\right)$ and $\left(\mathbf{p}_{j}, f_{j}\right)$ is $\left(\operatorname{lc}\left(f_{j}\right) / \operatorname{lc}\left(f_{i}\right)\right) t_{1}\left(\mathbf{p}_{j}, f_{j}\right)$. Note that $\left(\operatorname{lc}\left(f_{i}\right) / \mathrm{lc}\left(f_{j}\right)\right) t_{1}\left(\mathbf{p}_{j}, f_{j}\right)$ is a J pair formed from $G_{s}$, and there must exist some pair say $\left(\mathbf{p}_{\ell}, f_{\ell}\right) \in G_{s}$, such that $\operatorname{lt}\left(\mathbf{p}_{\ell}\right) \mid\left(\operatorname{lc}\left(f_{i}\right) / \operatorname{lc}\left(f_{j}\right)\right) t_{1} \operatorname{lt}\left(\mathbf{p}_{j}\right)$ and $t_{3} \operatorname{lm}\left(f_{\ell}\right)<t_{1} \operatorname{lm}\left(f_{j}\right)$ with $t_{3}=t_{1} \operatorname{lm}\left(\mathbf{p}_{j}\right) / \operatorname{lm}\left(\mathbf{p}_{\ell}\right)$. Since $\operatorname{lc}\left(\mathbf{p}_{\ell}\right) \mid\left(\operatorname{lc}\left(f_{i}\right) / \operatorname{lc}\left(f_{j}\right)\right) \operatorname{lc}\left(\mathbf{p}_{j}\right)$, set $a_{3}=\left(\operatorname{lc}\left(f_{i}\right) / \operatorname{lc}\left(f_{j}\right)\right) \cdot\left(\operatorname{lc}\left(\mathbf{p}_{j}\right) / \operatorname{lc}\left(\mathbf{p}_{\ell}\right)\right)$, and then,

$$
\begin{aligned}
\frac{a}{\left(\operatorname{lc}\left(f_{i}\right) / \operatorname{lc}\left(f_{j}\right)\right)} a_{3} t_{3} w \operatorname{lt}\left(\mathbf{p}_{\ell}\right)= & \frac{a}{\left(\operatorname{lc}\left(f_{i}\right) / \operatorname{lc}\left(f_{j}\right)\right)} \frac{\operatorname{lc}\left(f_{i}\right)}{\operatorname{lc}\left(f_{j}\right)} t_{1} w \operatorname{lc}\left(\mathbf{p}_{j}\right) \cdot \operatorname{lm}\left(\mathbf{p}_{j}\right)=a t_{1} w \operatorname{lt}\left(\mathbf{p}_{j}\right)=a t \operatorname{lt}\left(\mathbf{p}_{j}\right)=T, \\
& t_{3} w \operatorname{lm}\left(f_{\ell}\right)<w t_{1} \operatorname{lm}\left(f_{j}\right)=t \operatorname{lm}\left(f_{j}\right) .
\end{aligned}
$$

This contradicts the condition (ii) for the selection of $\left(\mathbf{p}_{j}, f_{j}\right)$ in $G_{s}$.

Let

$$
(\widetilde{\mathbf{p}}, \tilde{f})=(\mathbf{p}, f)-a t\left(\mathbf{p}_{j}, f_{j}\right),
$$

and then, $\operatorname{lm}(\widetilde{\mathbf{p}})<\operatorname{lm}(\mathbf{p})$ and $\operatorname{lt}(f) \neq a \operatorname{lt}\left(f_{j}\right)$. Otherwise, $(\mathbf{p}, f)$ would be top-reduced by $\left(\mathbf{p}_{j}, f_{j}\right)$ which contradicts with the selection of $(\mathbf{p}, f)$. So, $\widetilde{f} \neq 0$ and $(\widetilde{\mathbf{p}}, \widetilde{f})$ can be topreduced by $G_{s}$ as $(\widetilde{\mathbf{p}}, \widetilde{f}) \in M$ and $\operatorname{lm}(\widetilde{\mathbf{p}})<\operatorname{lm}(\mathbf{p}), \operatorname{lt}(\widetilde{\mathbf{p}})<\operatorname{lt}(\mathbf{p})$, say it is top-reduced by $\left(\mathbf{p}_{k}, f_{k}\right)$. If $f_{k}=0$, we use this type of pairs to reduce $(\widetilde{\mathbf{p}}, \widetilde{f})$ as much as possible and obtain a new pair $\left(p^{\prime}, \tilde{f}\right)$ finally, which cannot be top-reduced by the same type of pairs (here, it refers the pairs whose $f$-part is zero) in $G_{s}$. Since $\left(p^{\prime}, \tilde{f}\right) \in M$ and $\operatorname{lm}\left(p^{\prime}\right)<\operatorname{lm}(\mathbf{p})$, lt $\left(p^{\prime}\right)<\operatorname{lt}(\mathbf{p})$, and then $\left(p^{\prime}, f\right)$ can be top-reduced by $G_{s}$, say by $\left(\mathbf{p}_{k}^{\prime}, f_{k}^{\prime}\right), f_{k}^{\prime} \neq 0$. For $\operatorname{lt}(f) \neq \operatorname{atlt}\left(f_{j}\right)$, there are the following three cases that need to be considered:

(i) If $\operatorname{lm}(f)<t \operatorname{lm}\left(f_{j}\right)$, then $\operatorname{lt}(\tilde{f})=a t \operatorname{lt}\left(f_{j}\right)$; but $\operatorname{lm}\left(p^{\prime}\right)<t \operatorname{lm}\left(\mathbf{p}_{j}\right)$, so there must exist some pairs in $G_{s}$ that can regular top-reduce at $\left(\mathbf{p}_{j}, f_{j}\right)$; assume the pair in $G_{s}$ is $\left(\mathbf{p}_{k}^{\prime}, f_{k}^{\prime}\right)$. This is impossible as at $\left(\mathbf{p}_{j}, f_{j}\right)$ cannot be regular top-reduced by any pair in $G_{s}$.

(ii) If $\operatorname{lm}(f)>t \operatorname{lm}\left(f_{j}\right)$, then $\operatorname{lm}(\tilde{f})=\operatorname{lm}(f)$, and $(\mathbf{p}, f)$ can be regular top-reduced by $\left(\mathbf{p}_{k}, f_{k}\right)$; this contradicts the choice of $(\mathbf{p}, f)$. (iii) If $\operatorname{lm}(f)=t \operatorname{lm}\left(f_{\mathrm{j}}\right)$ and $\operatorname{lc}(f) \neq a \operatorname{alc}\left(f_{\mathrm{j}}\right),(\tilde{\mathbf{p}}, \tilde{f})$ is top-reduced by $\left(\mathbf{p}_{k}^{\prime}, f_{k}^{\prime}\right)$, and then, $\operatorname{lt}\left(f_{k}^{\prime}\right) \mid \operatorname{lt}(\widetilde{f})$; this means that $\operatorname{lm}\left(f_{l}^{\prime}\right) \mid \operatorname{lm}(\tilde{f})$ and $\operatorname{lc}\left(f_{k}^{\prime}\right) \mid \mathrm{lc}$ $(\tilde{f})=\operatorname{lc}(f)-\operatorname{alc}\left(f_{j}\right)$.

From the property of valuation ring, we consider the relation between $\operatorname{alc}\left(f_{j}\right)$ and $\operatorname{lc}(f)$ in the following three cases:

(a) If $a \operatorname{lc}\left(f_{j}\right)=b \operatorname{lc}(f)$ and $b$ is not a nonzero unit, note that a valuation ring is a local ring, and $b$ is in the unique maximal ideal. Since $\operatorname{lc}\left(f_{k}^{\prime}\right) \mid \operatorname{lc}(f)-a \operatorname{lc}\left(f_{j}\right)=$ $(1-b) \operatorname{lc}(f)$ and $1-b$ is invertible, then $\operatorname{lc}\left(f_{k}^{\prime}\right) \mid \operatorname{lc}(f)$. Note that $\left(\operatorname{lm}(f) / \operatorname{lm}\left(f_{k}^{\prime}\right)\right) \operatorname{lm}\left(\mathbf{p}_{k}^{\prime}\right)<\operatorname{lm}\left(p^{\prime}\right)<\operatorname{lm}(\mathbf{p})$ and $(\mathbf{p}, f)$ are regular top-reduced by $\left(\mathbf{p}_{k}, f_{k}\right)$; this contradicts the choice of $(\mathbf{p}, f)$.

(b) If $a \operatorname{lc}\left(f_{j}\right) \cdot b=\operatorname{lc}(f)$ and $b$ is not a nonzero unit, note that a valuation ring is a local ring, and $b$ is in the unique maximal ideal. Since $\operatorname{lc}\left(f_{k}^{\prime}\right) \mid \operatorname{lc}(f)-$ $\operatorname{alc}\left(f_{j}\right)=(1-b) \operatorname{alc}\left(f_{j}\right)$ and $1-b$ is invertible, then $\operatorname{lc}\left(f_{k}^{\prime}\right) \mid \operatorname{alc}\left(f_{j}\right)$. Note that $\left(t \operatorname{lm}\left(f_{j}\right) / \operatorname{lm} \quad\left(f_{\ell}^{\prime}\right)\right) \operatorname{lm}$ $\left(\mathbf{p}_{k}^{\prime}\right)<\operatorname{lm}\left(p^{\prime}\right)<\operatorname{lm}(\mathbf{p})=t \operatorname{lm}\left(\mathbf{p}_{j}\right)$, then at $\left(\mathbf{p}_{j}, f_{j}\right)$ is regular top-reduced by $\left(\mathbf{p}_{k}, f_{k}\right)$, and this case is impossible.

(c) If $a \operatorname{lc}\left(f_{j}\right)=b \operatorname{lc}(f)$ and $b$ is a nonzero unit, then $\operatorname{alc}\left(f_{j}\right) \mid \operatorname{lc}(f)$ and $\left(\operatorname{lc}(f) / a \operatorname{lc}\left(f_{j}\right)\right)=b^{-1}$. Note that $\operatorname{lt}(\mathbf{p})=\operatorname{atlt}\left(\mathbf{p}_{j}\right)$; combining the definition of the 
order, we have $b^{-1} \cdot \operatorname{alt}\left(\mathbf{p}_{j}\right) \prec \operatorname{lt}(\mathbf{p})$. Therefore, $(\mathbf{p}, f)$ can be top-reduced by at $\left(\mathbf{p}_{j}, f_{j}\right)$, and this contradicts the choice of $(\mathbf{p}, f)$.

Thus, such pairs like $(\mathbf{p}, f)$ cannot exist in $M$ at all; hence, all pairs of $M$ can be top-reduced by $G_{s}$, and $G_{s}$ is a strong Gröbner basis for $M$.

The pair $p=(\mathbf{p}, f)$ is covered by $G_{s}$ when there exists at least one pair such as $p_{1}=\left(\mathbf{p}_{1}, f_{1}\right)$ in $G_{s}$, such that $\operatorname{lt}\left(\mathbf{p}_{1}\right) \mid \operatorname{lt}(\mathbf{p})$ and $t \operatorname{lm}\left(f_{1}\right)<\operatorname{lm}(f)$, where $t=\operatorname{lm}(\mathbf{p}) / \operatorname{lm}\left(\mathbf{p}_{1}\right)$.

Theorem 2. Suppose $G_{s}$ is a special subset of $M$, whose particularity is reflected in for any term $T \in R^{m}$, there always exists a pair $\left(\mathbf{p}_{i}, f_{i}\right) \in G_{s}$ and monomial $t \in R$ and $a \in V$, such that $T=\operatorname{atlt}\left(\mathbf{p}_{i}\right)$. Then, $G_{s}$ is a strong Gröbner basis for $M$ if the factors of the $J$ pairs formed by $G_{s}$ can always be eventually super top-reduced by the set $G_{s}$.

Proof. Assume that $t_{1}\left(\mathbf{p}_{1}, f_{1}\right), t_{2}\left(\mathbf{p}_{2}, f_{2}\right)$ are the two J pairs formed by $G$, and $t_{1}\left(\mathbf{p}_{1}, f_{1}\right)$ is a factor of $t_{2}\left(\mathbf{p}_{2}, f_{2}\right)$. Then, $t_{1}\left(\mathbf{p}_{1}, f_{1}\right)$ can be eventually super top-reducible by $G_{s}$, that is, after doing a series of regular top-reduction to $t_{1}\left(\mathbf{p}_{1}, f_{1}\right)$, say it to get $\left(p^{\prime}, f^{\prime}\right)$ where $\operatorname{lt}\left(p^{\prime}\right)=t_{1} \operatorname{lm}\left(\mathbf{p}_{1}\right), \operatorname{lt}\left(f^{\prime}\right)<t_{1} \operatorname{lt}\left(f_{1}\right)$; besides, $\left(p^{\prime}, f^{\prime}\right)$ can be super top-reduced by $G_{s}$, say $\left(\mathbf{p}_{i}, f_{i}\right)$; then, $a_{i} \operatorname{lt}\left(\mathbf{p}_{i}\right)=t_{1}$ lt $\left(\mathbf{p}_{1}\right), a_{i} t_{i} \operatorname{lt}\left(f_{i}\right)<t_{1} \operatorname{lt}\left(f_{1}\right)$, where $a_{i} t_{i}=($ lt $\left.\left(f^{\prime}\right) / \mathrm{lt}\left(f_{i}\right)\right)$. Clearly, $t_{2}\left(\mathbf{p}_{2}, f_{2}\right)$ can be covered by $\left(\mathbf{p}_{i}, f_{i}\right)$. It is also correct for the rest of $J$ pairs and their factors. By Theorem 1 , we have that $G_{s}$ is a strong Gröbner basis for $M$.

According to Theorems 1 and 2, we can discard the J pairs which can be covered by $G_{s}$ without doing any regular nor super top-reductions. As a consequence, there are four criteria for discarding redundant $J$ pairs.

Corollary 1. (Covered criterion) For any J pair $(\mathbf{p}, f)$ of $G_{s}$, it can be discard if $(\mathbf{p}, f)$ is covered by $G_{s}$.

Corollary 2. (Syzygy criterion) If a J pair $(\mathbf{p}, f)$ can be topreduced by a syzygy, then it can be discarded.

Corollary 3. (Signature criterion) As for the J pairs with the same signature, we only need to keep the one whose $f$-part is minimal.

Corollary 4. (Factor criterion) As for the J pair which has a factor, we just need to keep the factor.

\section{Algorithm and Example}

According to the theorems and corollaries in Section 3, we can get an algorithm for computing Gröbner bases for the polynomial ideals over valuation domains. We call the algorithm as VID - GVW. The main idea of VID - GVW is analogue to the GVW algorithm of principal ideal domain [23]. First, we form J pairs by the initial pairs $\left(\mathbf{e}_{1}, g_{1}\right), \ldots,\left(\mathbf{e}_{m}, g_{m}\right)$. By Theorems 1 and 2 , we just store the $J$ pairs with different signatures. We only consider the J pairs that we store, choose any one of them, denoted as $(\mathbf{p}, f)$, and then check whether it satisfies Corollary 1 , that is, whether it is covered by $G_{s}$. If so, discard it. Otherwise, delete all the J pairs whose factor is $(\mathbf{p}, f)$ and perform regular top-reductions to it repeatedly until it cannot be regular top-reduced any more, say to get $\left(p^{\prime}, f^{\prime}\right)$ finally. If $f^{\prime}=0$, then $p^{\prime}$ is a syzygy in $\mathbf{H}$. We add it to $\mathbf{H}$ and delete the pairs whose signature is divisible by $\operatorname{lt}\left(p^{\prime}\right)$. Otherwise, $\left(p^{\prime}, f^{\prime}\right)$ adds to the set JP, and we will not stop the process until the set of J pair is empty. In the while-loop, all the J pairs formed from $G_{s}$ will be top-reduced by the set $G_{s}$. We describe the algorithm in more detail and accurately with Figure $1 . \mathbf{H}$ is used to store the leading terms of syzygies; the Gröbner basis we get is a list of pairs $\left(T_{1}, f_{1}\right),\left(T_{2}, f_{2}\right), \ldots,\left(T_{k}, f_{k}\right)$, where $f_{j} \neq 0$ for $1 \leq j \leq k$. We store this list as

$$
\begin{aligned}
P & =\left[T_{1}, T_{2}, \ldots, T_{k}\right], \\
F & =\left[f_{1}, f_{2}, \ldots, f_{k}\right] .
\end{aligned}
$$

So the whole list $\left(T_{1}, f_{1}\right),\left(T_{2}, f_{2}\right), \ldots,\left(T_{k}, f_{k}\right)$ is represented by $[P, F]$.

Theorem 3. Assume the term orders in $R$ are compatible with which in $R^{m}$; then, the algorithm shown in Figure 1 will terminate after a finite number of steps and get a strong Gröbner basis for $M$.

Proof. The correctness of our algorithm is obviously according to Theorems 1 and 2. As for the termination of the algorithm, we can refer to the Theorem 1 in [21].

Next, we present our algorithm and use a concrete example to demonstrate the improvement clearly.

Example 1. Let $V[x, y]=\mathbb{Z}_{\left(3^{3}\right)}[x \cdot y]$, and we consider the Gröbner basis of the ideal $I=\left\langle f_{1}, f_{2}, f_{3}\right\rangle \in V[x, y]$, where

$$
\begin{aligned}
& f_{1}=x^{2} y-x, \\
& f_{2}=x y^{2}-x y, \\
& f_{3}=y^{3},
\end{aligned}
$$

and $\mathbb{Z}_{\left(3^{3}\right)}$ is a discrete valuation ring, for each prime $p$ (here is 3$)$; set $v_{p}: Q^{*} \longrightarrow \mathbb{Z}$ is a function given by $v_{p}\left(p^{k} a / b\right)=k$ if $a, b$ are integers relatively prime to $p$.

The term order we set on $V[x, y]$ is the lexicographical ordering, which is defined by $y<x$. Besides, the term order $<$ on $V^{m}[x, y]$ is $x^{\alpha} \mathbf{e}_{i}<x^{\beta} \mathbf{e}_{j}$ if $i<j$ or $i=j$ and $x^{\alpha}<x^{\beta}$.

First, let $[P, F]=\left\{\left(\mathbf{e}_{1}, f_{1}\right),\left(\mathbf{e}_{2}, f_{2}\right),\left(\mathbf{e}_{3}, f_{3}\right)\right\}$; then, $H=\left\{x y^{2} \mathbf{e}_{1}, y^{3} \mathbf{e}_{1}, y^{3} \mathbf{e}_{2}\right\}$, which is a set that stands for leading term of principle syzygy.

Choose $\left(\mathbf{e}_{1}, f_{1}\right),\left(\mathbf{e}_{2}, f_{2}\right)$ from $[P, F]$; then, $\operatorname{lcm}\left(\operatorname{lm}\left(f_{1}\right), \operatorname{lm}\left(f_{2}\right)\right)=x^{2} y^{2}$. Hence, $t_{1}=y, t_{2}=x$, and $J$ pair of $\left(\mathbf{e}_{1}, f_{1}\right)$ and $\left(\mathbf{e}_{2}, f_{2}\right)$ is $y\left(\mathbf{e}_{1}, f_{1}\right)$, whose signature cannot be reduced by $H$, and we store it.

Doing the same process, the $J$-pairs set of other pairs in $[P, F]$ is $\left\{y^{2}\left(\mathbf{e}_{1}, f_{1}\right), y\left(\mathbf{e}_{2}, f_{2}\right)\right\}$, but $y\left(\mathbf{e}_{1}, f_{1}\right)$ is a factor of $y^{2}\left(\mathbf{e}_{1}, f_{1}\right)$, so delate. Then,

$$
\mathrm{JP}=\left\{y\left(\mathbf{e}_{1}, f_{1}\right), y\left(\mathbf{e}_{2}, f_{2}\right)\right\} .
$$

Selecting $y\left(\mathbf{e}_{2}, f_{2}\right)$ from JP, we get $\left((y+1) \mathbf{e}_{2}-x \mathbf{e}_{3},-x y\right)$ after a series of regular top-reduction, add it to $[P, F]$, and recalculate the J pairs and 


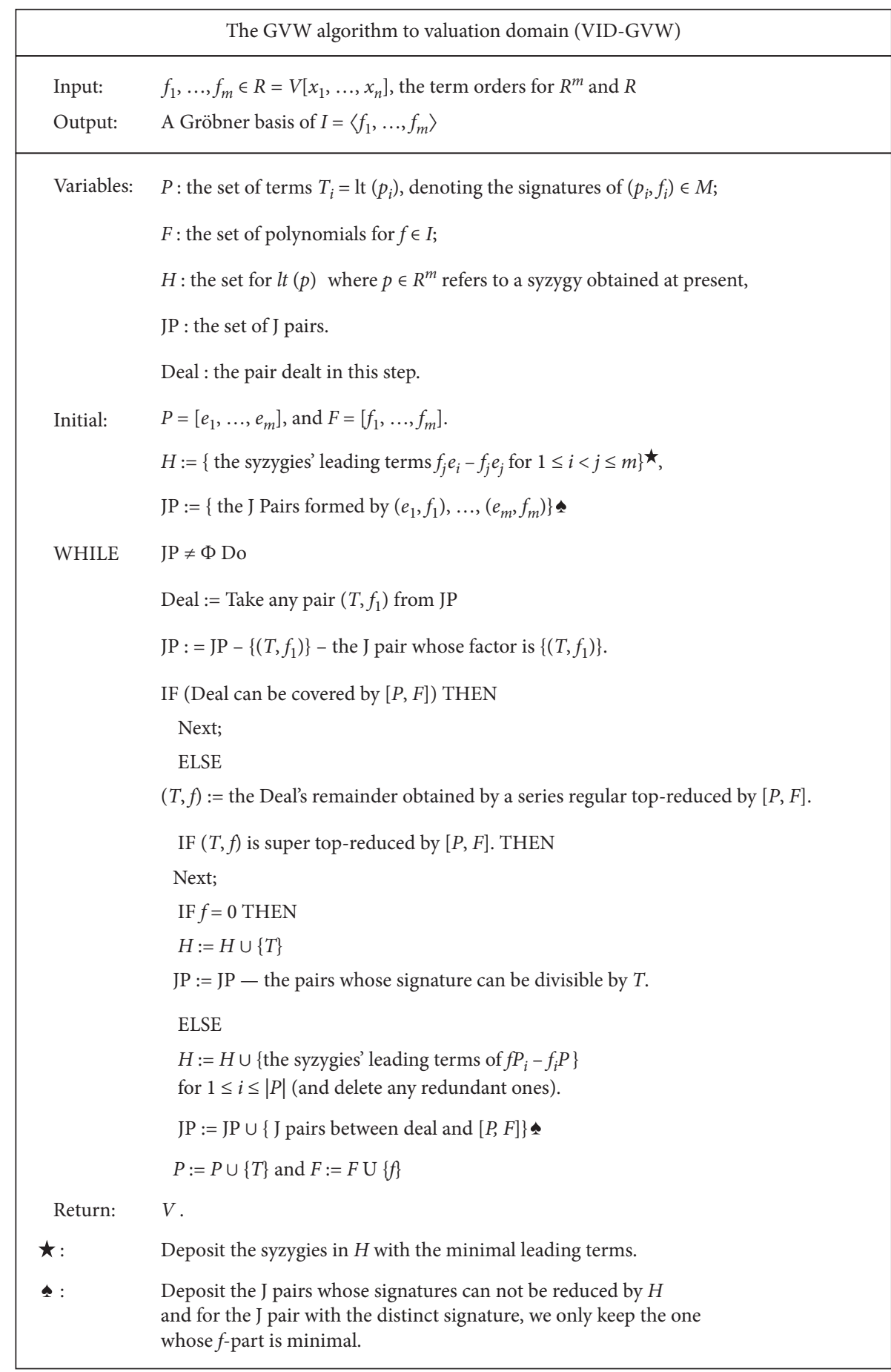

FIgURE 1: VID-GVW.

$$
H=\left\{x y^{2} \mathbf{e}_{1}, y^{3} \mathbf{e}_{1}, y^{3} \mathbf{e}_{2}\right\} .
$$

Using the syzygy criterion and factor criterion, we obtain

$$
\mathrm{JP}=\left\{y\left(\mathbf{e}_{1}, f_{1}\right), y\left((y+1) \mathbf{e}_{2}-x \mathbf{e}_{3},-x y\right)\right\} .
$$

Select $y\left((y+1) \mathbf{e}_{2}-x \mathbf{e}_{3},-x y\right)$ from JP; it can be regular top-reduced to $\left.\left(y(y+1) \mathbf{e}_{2}-x \mathbf{e}_{3}, 0\right)\right)$ and add $y^{2} \mathbf{e}_{2}$ to $H$.

Select $y\left(\mathbf{e}_{1}, f_{1}\right)$ from JP; it can be regular top-reduced to $\left.\left(y \mathbf{e}_{1}, 0\right)\right)$ and add $y \mathbf{e}_{1}$ to $H$.
Now, JP $=\varnothing$. So $\left\{x^{2} y-x, x y^{2}-x y, y^{3},-x y\right\}$ is a strong Gröbner basis for $I$ in $V[x, y]$.

\section{Conclusions}

In this study, we have generalized the GVW algorithm and presented an algorithm to compute Gröbner bases for polynomial ideals over valuation domains. We have also given an example to illustrate our method. All of these could provide useful information for engineers to solve large linear 
systems and networked dynamical systems. Valuation domains are special kinds of valuation rings which may have zero divisors. In the future, we want to consider new algorithms for Gröbner bases of ideals over general valuation rings. And we also hope to establish a dynamical Gröbner basis algorithm which combined with the algorithm in the study.

\section{Data Availability}

The data used to support the findings of this study are included within the article.

\section{Conflicts of Interest}

The authors declare that there are no conflicts of interest.

\section{Acknowledgments}

This research was supported by the National Natural Science Foundation of China (11871207).

\section{References}

[1] B. Buchberger, "An algorithm for finding a basis for the redidue class ring of a zero dimensiomal polynomial," $\mathrm{Ph}$. D. thesis, Universität Innsbruck, Institut für Mathematik, Innsbruck, Austria, 1965.

[2] D. Li, J. Liu, and L. Zheng, "On the equivalence of multivariate polynomial matrices," Multidimensional Systems and Signal Processing, vol. 28, no. 1, pp. 225-235, 2017.

[3] J. Zhang and H. Su, "Formation-containment control for multi-agent systems with sampled data and time delays," Neurocomputing, vol. 424, pp. 125-131, 2021.

[4] Y. Liu and H. Su, "Some necessary and sufficient conditions for containment of second-order multi-agent systems with sampled position data," Neurocomputing, vol. 378, pp. 228$237,2020$.

[5] Y. Liu and H. Su, "Containment control of second-order multi-agent systems via intermittent sampled position data communication," Applied Mathematics and Computation, vol. 362, Article ID 124522, 2019.

[6] C. Xu, H. Xu, H. Su, and C. Liu, "Disturbance-observer based consensus of linear multi-agent systems with exogenous disturbance under intermittent communication," Neurocomputing, vol. 404, pp. 26-33, 2020.

[7] C. $\mathrm{Xu}, \mathrm{B} . \mathrm{Li}$, and L. Yang, "Semi-global containment of discrete-time high-order multi-agent systems with input saturation via intermittent control," IET Control Theory \& Applications, vol. 14, no. 16, pp. 2303-2309, 2020.

[8] C. Zhao, S. Zhong, X. Zhang, Q. Zhong, and K. Shi, "Novel results on nonfragile sampled-data exponential synchronization for delayed complex dynamical networks," International Journal of Robust and Nonlinear Control, vol. 30, no. 10, pp. 4022-4042, 2020.

[9] C. Zhao, S. Zhong, Q. Zhong, and K. Shi, "Synchronization of Markovian complex networks with input mode delay and Markovian directed communication via distributed dynamic event-triggered control," Nonlinear Analysis: Hybrid Systems, vol. 36, Article ID 100883, 2020.

[10] X. Cai, J. Wang, S. Zhong, K. Shi, and Y. Tang, "Fuzzy quantized sampled-data control for extended dissipative analysis of T-S fuzzy system and its application to WPGSs," Journal of the Franklin Institute, vol. 358, no. 2, pp. 1350-1375, 2021.

[11] K. Shi, J. Wang, S. Zhong, Y. Tang, and J. Cheng, "Non-fragile memory filtering of T-S fuzzy delayed neural networks based on switched fuzzy sampled-data control," Fuzzy Sets and Systems, vol. 394, pp. 40-64, 2020.

[12] K. Shi, J. Wang, Y. Tang, and S. Zhong, "Reliable asynchronous sampled-data filtering of T-S fuzzy uncertain delayed neural networks with stochastic switched topologies," Fuzzy Sets and Systems, vol. 381, pp. 1-25, 2020.

[13] X. Cai, S. Zhong, J. Wang, and K. Shi, "Robust Hoo control for uncertain delayed T-S fuzzy systems with stochastic packet dropouts," Applied Mathematics and Computation, vol. 385, Article ID 125432, 2020.

[14] B. Buchberger, "A criterion for detecting unnecessary reductions in the construction of Gröbner bases," in EUROSAM'79: Proceedings of the International Symposiumon on Symbolic and Algebraic Computation, pp. 3-21, Marseille, France, June 1979.

[15] B. B.. Gröbner-Bases, An Algorithmic Method in Polynomial Ideal Theory, Reidel Publishing Company, Dordrecht, Netherlands, 1985.

[16] N. Courtois, A. Klimov, J. Patarin, and A. Shamir, "Efficient algorithms for solving overdefined systems of multivariate polynomial equations," Advances in Cryptology-EUROCRYPT 2000, Springer-Verlag, Berlin, Germany, pp. 392-407, 2000.

[17] C. Eder and J. Perry, "F5C: a variant of Faugere's F5 algorithm with reduced Gröbner bases," Journal of Symbolic Computation, vol. 45, no. 12, pp. 1442-1458, 2009.

[18] Y. Sun and D. Wang, "F5B: A new proof of the F5 algorithm," 2010, http://arxiv.org/abs/1004.0084.

[19] J. C. Faugere, "A new effcient algorithm for computing Gröbner bases without reduction to zero (F5)," in ISSAC 02: Proceedings of the 2002 International Symposium on Symbolic and algebraic computation, pp. 75-83, Lille, France, July 2002.

[20] S. Gao, Y. Guan, and F. Volny, "A new incremental algorithm for computing Gröbner bases," in ISSAC 10: Proceedings of the 2010 International Symposium on Symbolic and Algebraic Computation, pp. 13-19, München, Germany, July 2010.

[21] S. Gao, F. Volny, and M. Wang, "A new framework for computing Gröbner bases," Mathematics of Computation, vol. 85, no. 297, pp. 449-465, 2015.

[22] D. Li, J. Liu, and L. Zheng, "A zero-dimensional valuation ring is 1-Gröbner," Journal of Algebra, vol. 484, pp. 334-343, 2017.

[23] D. Li, J. Liu, W. Liu, and L. Zheng, "GVW algorithm over principal ideal domains," Journal of Systems Science and Complexity, vol. 26, no. 4, pp. 619-633, 2013.

[24] D. M. Li and J. W. Liu, "A Gröbner basis algorithm for ideals over zero-dimensional valuation rings," Journal of Systems Science and Complexity, vol. 33, pp. 1-14, 2020. 